OPEN ACCESS

Edited by:

Fedor N. Shkil,

Severtsov Institute of Ecology and Evolution, Russian Academy

of Sciences (RAS), Russia

Reviewed by:

Gayani Senevirathne,

Harvard University, United States

Maja Ajdukovic,

University of Belgrade, Serbia

*Correspondence:

Marissa Fabrez

mfabrezi@conicet.gov.ar

Specialty section:

This article was submitted to Evolutionary Developmental Biology,

a section of the journal

Frontiers in Ecology and Evolution

Received: 27 May 2021

Accepted: 07 October 2021

Published: 26 October 2021

Citation:

Fabrezi M and Cruz JC (2021)

Phenotypic Variation Through Ontogeny: Thyroid Axis Disruption

During Larval Development

in the Frog Pleurodema borellii.

Front. Ecol. Evol. 9:715988.

doi: 10.3389/fevo.2021.715988

\section{Phenotypic Variation Through Ontogeny: Thyroid Axis Disruption During Larval Development in the Frog Pleurodema borellii}

\author{
Marissa Fabrezi* and Julio César Cruz \\ Instituto de Bio y Geociencias del NOA (IBIGEO), CCT CONICET Salta-Jujuy, Rosario de Lerma, Salta, Argentina
}

Studies of the effects of thyroid hormones on larval development in the frog Xenopus spp. have provided baseline information to identify developmental constraints and elucidate genetic and hormonal mechanisms driving development, growth, and life history transitions. However, this knowledge requires data based on other anurans to complete a comprehensive approach to the understanding of larval developmental diversity and phenotypic variation through ontogeny. Mesocosm experiments provide realistic data about environmental conditions and timing; this information is useful to describe anuran larval development and/or analyze endocrine disruption. In this study, mesocosm experiments of the larval development of the frog Pleurodema borellii were conducted to explore the consequences of thyroid axis disruption; the sensitivity of tadpoles to the methimazole $(2.66 \mathrm{mg} / \mathrm{l})$ and thyroxine (T4) $(1.66 \mu \mathrm{g} / \mathrm{l})$ was compared. These concentrations were selected based on previous studies in Pleurodema borellii. We test the effects of methimazole and thyroxine on development in early exposure (from beginning of larval development) and late exposure, 18 days after hatching, with doses administered every $48 \mathrm{~h}$. Tadpoles were evaluated 31 days after hatching. Methimazole caused moderate hypertrophy of the thyroid gland, alteration in the growth rates, differentiation without inhibition of development, and an increase of developmental variability. Thyroxine produced slight atrophy of the thyroid gland, accelerated growth rates and differentiation, and minor developmental variability. In tadpoles at stages previous to metamorphose, skull development (differentiation of olfactory capsules, appearance of dermal bones, and cartilage remodeling) seemed to be unaltered by the disruptors. Moreover, similar abnormal morphogenesis converged in specimens under methimazole and thyroxine exposures. Abnormalities occurred in pelvic and pectoral girdles, and vent tube, and could have been originated at the time of differentiation of musculoskeletal tissues of girdles. Our results indicate that premetamorphic stages (Gosner Stages 25-35) are sensitive to minimal thyroid axis disruption, which produces changes in developmental rates; these stages would also be critical for appendicular musculoskeletal morphogenesis to achieve the optimal condition to start metamorphosis.

Keywords: methimazole, thyroid hormone, tadpole, metamorphosis, growth, differentiation, anurans 


\section{INTRODUCTION}

Endocrine disruptors are chemicals that can interfere with endocrine systems. Among vertebrates, the thyroid gland is a vital endocrine gland with special role in the metabolism, growth and development. Thyroid disruptors are well known since some substances, named goitrogens, cause difficulty for the synthesis of thyroid hormones producing the enlargement of the thyroid gland to compensate the inadequate hormone production. Among these substances, the methimazole is used to treat the hyperthyroidism. Differently, the thyroid hormone (thyroxine, T4) is supplied when the thyroid gland doesn't produce enough hormone (i.e., hypothyroidism).

Studies of the effects of thyroid hormones (THs) [i.e., triiodothyronine (T3) and thyroxine (T4)] on anuran larval development have been key to identifying developmental constraints and have provided a framework to improve our understanding of cell behavior and the molecular mechanisms underlying growth and metamorphic remodeling (Shi, 2000; Buchholz, 2017; Rose and Cahill, 2019; Rose, 2021). Most of these studies were based on the frog model system Xenopus laevis and/or Xenopus tropicalis, and were focused on skull and gut remodeling (Hanken and Summers, 1988; Schreiber et al., 2005; Smirnov and Vassilieva, 2014; Rose et al., 2015; Choi et al., 2017; Rose and Cahill, 2019), tail disappearance (Yaoita, 2019), differentiation of morphological novelties (Senevirathne et al., 2020), and the systemic consequences of the spontaneous absence of thyroid glands (Rot-Nikcevic and Wassersug, 2003, 2004). This model system represents a basal lineage with a whole ontogeny that displays many eco-morphological differences with respect to most anurans; thus, information needs to be complemented with data on anuran larval development diversity to explain adaptive differentiation (Roelants et al., 2011). Further, studies in the direct developer frog Eleutherodactylus coqui (Jennings and Hanken, 1998; Callery and Elinson, 2000; Laslo et al., 2019) have proposed the conservation of thyroid gland physiology in absence of typical metamorphic transformations which is observed in other lineages of frogs without free living tadpoles (Naumann et al., 2020).

The knowledge about the anuran thyroid physiology has provided some generalizations for larval development. The normal histomorphology (e.g., size and histology) of the thyroid gland may be divided into phases correlated with larval development (Etkin, 1936) as follows: (a) the gland is small, with follicular cells with poor cytoplasm during limb bud stages and stages of digit differentiation (premetamorphosis); (b) the gland grows and follicular cells become columnar during stages of limb growth (prometamorhosis); and (c) the gland reduces by collapse of follicles, and the epithelium achieves a condition almost squamous (metamorphic climax). In this way, the thyroid gland histology offers an important diagnosis of several histomorphological features modulated by the hypothalamicpituitary-thyroid (HPT) regulatory axis. Thyroid histology serves as a valuable and sensitive diagnostic to detect the ability of a chemical to interact with the HPT axis (Grim et al., 2009).

Moreover, the expression of enzyme deiodinases on thyroid hormone and thyroid hormone receptors (TR $\alpha)$ during premetamorphosis are involved in limb differentiation
(Cai and Brown, 2004) whereas expression of deiodinases and thyroid hormone receptors $(\operatorname{TR} \beta)$ trigger several morphological changes typical of metamorphosis (Choi et al., 2017). These studies denote differences in temporal sensitivity and receptors between the appendicular system and most larval organs and systems that are lost or remodeled at the metamorphic climax when the levels of hormones increase. Additionally, THs play an important role in the regulation of anuran cranial ontogeny, influencing the timing and sequences of cartilage transformation and bone appearance as well as bone growth. Artificial changes in the TH-level can lead to considerable temporary changes in skull development in some anurans (Smirnov and Vassilieva, 2009; Rose and Cahill, 2019; Rose, 2021). Experimental studies showed that the axial skeleton ossification of most neural arches is not dependent on or only requires a low level of TH. However, $\mathrm{TH}$ is necessary to induce ossification in the most posterior arches and the ribs. Similarly in the hind limb skeleton, the cartilaginous precursors of bone elements fail to ossify in $\mathrm{TH}$ absence (Smirnov and Vassilieva, 2014). The premetamorphic histomorphology of the thyroid gland and the early sensitivity of limbs suggest the hormone concentrations define rates of development that may accelerate or delay the timing to start the metamorphosis when minimal changes occur.

Mesocosm experiments provide realistic data about environmental conditions and timing; thus, those experiments are useful to describe anuran larval development and are suitable to analyze developmental rates (Skelly and Kiesecker, 2001). Recently, mesocosm experiments of three anuran species (Pleurodema borellii, Leptodactylus chaquensis, and Dermatonotus muelleri) reported differential responsiveness and sensitivity to endocrine disruptors in tadpoles exposed from premetamorphic stages (Fabrezi et al., 2019). At similar concentrations of $\mathrm{T} 4$, developmental rates were modified, as evidenced in body size, histomorphology of the thyroid gland, limb development, and metamorphic transformations were triggered in gut and skull cartilage remodeling in two species (e.g., Leptodactylus chaquensis and Dermatonotus muelleri), whereas methimazole increased growth rates in Pleurodema borellii (Fabrezi et al., 2019).

Pleurodema borellii (Peracca, 1895) is a common frog present in the northwest of Argentina; reproduction and breeding occur during the wet season, eggs are laid in foam nests, tadpoles are typical of ephemeral ponds, with developmental stages identified by standard anuran staging table (Gosner, 1960; Cruz, 2020). Larval development in $P$. borellii shows intraspecific heterochronic variations, since tadpoles belonging to a single clutch complete the embryonic stages at the same time (6 days after fertilization), but larvae develop at different rates; then, after 20 days, tadpoles may reach stages of digit differentiation or remain at limb bud stages, suggesting different individual development under similar environmental variables (Fabrezi et al., 2019; this study).

Here, we present the results of mesocosm experiments in Pleurodema borellii larval development to explore the consequences of disruptors (methimazole and thyroxine) on the thyroid gland. Methimazole (CAS Number: 60-560 ) is considered an inhibitor of synthesis of the thyroid 
hormone, whereas thyroxine (CAS Number 51-48-9) is an endogenous agonist.

Tadpoles were immersed in predetermined concentrations at the beginning of larval development (early exposure, Gosner Stage 25), and after 18 days of hatching (late exposure). Larval exposure to disruptors began at an earlier development stage than in previous studies and finished later (Degitz et al., 2005; Fabrezi et al., 2019; Tables 1, 2).

We focused on the whole larval development to test the effects of disruptors to change developmental rates, either delaying or stimulating; thyroid gland histomorphology, and the condition under which metamorphosis may be achieved in a non-model species, Pleurodema borelli.

\section{MATERIALS AND METHODS}

A Pleurodema borellii (Peracca, 1895) clutch was deposited in an abandoned swimming pool of the Instituto de Bio y Geociencias
Noa $\left(24^{\circ} 59^{\prime} 3.54^{\prime \prime} \mathrm{S}, 65^{\circ} 34^{\prime} 53.13^{\prime \prime} \mathrm{W}\right)$ on January 6,2021 . The clutch was transferred to a container and held up to January 11 (Day 0), when the embryos hatch and showed opercular folds covering partially or totally external gills. Specimens were staged following the standard table of Gosner (1960) and Cruz (2020). Then, tadpoles were randomly distributed in groups of 60-70 tadpoles and maintained in 20 plastic containers $(40 \mathrm{~cm} \times 40 \mathrm{~cm} \times 30 \mathrm{~cm})$ with 151 of tap water within a large receptacle placed outdoor (Figure 1). Environmental conditions during the experiments varied, with temperatures ranging between 27 and $35^{\circ} \mathrm{C}$ during the day and 18 and $24^{\circ} \mathrm{C}$ at night, and rainfall of $106.5 \mathrm{~mm}$ distributed over 13 days. Each container was supplied with $1 \mathrm{~g}$ of tropical fish food once a day. Tadpole density for each container is considered low, since these species may breed in small ponds with higher densities.

The treatments started 2 days after hatching when most tadpoles were at Gosner Stage 25 with oral disc complete (Cruz, 2020). Four containers were identified

TABLE 1 | Comparison of studies of larval development of anuran species exposed to methimazole.

\begin{tabular}{|c|c|c|c|c|}
\hline Study & Species & Initial Stage & $\begin{array}{l}\text { Concentrations } \\
(\mathrm{mg} / \mathrm{l}) \text { and days of } \\
\text { exposure }\end{array}$ & Effects on thyroid histopathology and development \\
\hline $\begin{array}{l}\text { Degitz et al. (2005) } \\
\text { Laboratory conditions }\end{array}$ & Xenopus laevis & $\begin{array}{l}\text { Early exposure: Nieuwkoop } \\
\text { and Faber Stage } 51 \approx \\
\text { Gosner Stage } 30 \\
\text { Late exposure: Nieuwkoop } \\
\text { and FaberStage } 54 \approx \\
\text { Gosner Stage } 35\end{array}$ & $\begin{array}{c}6.25,12.5,25.0 \\
50.0,100 \\
14 \text { days }\end{array}$ & $\begin{array}{l}\text { Hypothyroidism: the severity in the thyroid gland is dependent of } \\
\text { concentration. Initial stage had no impact on the concentration at which } \\
\text { significant effects on developmental rate are observed. Significant } \\
\text { inhibition in development at concentrations above } 25.00 \mathrm{mg} / \mathrm{l} \text {. The span } \\
\text { of developmental stage at intermediate concentrations fell between the } \\
\text { controls and } 100 \mathrm{mg} / \mathrm{l} \text { treatment. }\end{array}$ \\
\hline \multirow[t]{2}{*}{$\begin{array}{l}\text { Fabrezi et al. (2019) } \\
\text { Mesocosm conditions }\end{array}$} & Pleurodema borellii & Gosner Stages 22-35 & $\begin{array}{l}6.6 \mathrm{mg} / \mathrm{l} \\
10 \text { days }\end{array}$ & $\begin{array}{l}\text { Moderate hypertrophy (20\%) of thyroid gland. Significant increment of } \\
\text { growth (Gosner Stages } 31-36) \text {. The span of developmental stage is } \\
\text { similar to the control }\end{array}$ \\
\hline & $\begin{array}{l}\text { Leptodactylus } \\
\text { macrosternum }\end{array}$ & Gosner Stages 28-30 & $\begin{array}{l}6.6 \mathrm{mg} / \mathrm{l} \\
16 \text { days }\end{array}$ & $\begin{array}{l}\text { Moderate hypertrophy ( } 27 \% \text { ) of thyroid gland. Significant increment of } \\
\text { tadpole size. The span of developmental stage is similar to the control }\end{array}$ \\
\hline
\end{tabular}

TABLE 2 | Comparison of studies of larval development of anuran species exposed to T4.

\begin{tabular}{|c|c|c|c|c|}
\hline Study & Species & Initial stage & $\begin{array}{l}\text { Concentrations } \\
(\mu \mathrm{g} / \mathrm{l}) \text { and days } \\
\text { of exposure }\end{array}$ & Effects on thyroid histopathology and development \\
\hline $\begin{array}{l}\text { Degitz et al. } \\
(2005) \\
\text { Laboratory } \\
\text { conditions }\end{array}$ & Xenopus laevis & $\begin{array}{l}\text { Early exposure: Nieuwkoop and } \\
\text { Faber Stage } 51 \approx \text { Gosner Stage } 30 \\
\text { Late exposure: Nieuwkoop and } \\
\text { FaberStage } 54 \approx \text { Gosner Stage } 35\end{array}$ & $\begin{array}{l}0.25,0.50,1.00 \\
2.00,4.00 \\
21 \text { days }\end{array}$ & $\begin{array}{l}\text { Increment in mortality at higher concentrations. Decrease in the number of } \\
\text { developmental stages related the increment of T4 concentrations. } \\
\text { Significant acceleration of development was observed at } 2 \text { and } 4 \mu \mathrm{g} / \mathrm{l} \text {. }\end{array}$ \\
\hline \multirow[t]{3}{*}{$\begin{array}{l}\text { Fabrezi et al. } \\
(2019) \\
\text { Mesocosm } \\
\text { conditions }\end{array}$} & $\begin{array}{l}\text { Pleurodema } \\
\text { borellii }\end{array}$ & Gosner Stages 22-35 & $\begin{array}{c}0.83 \\
10 \text { days }\end{array}$ & Moderate atrophy of thyroid gland. \\
\hline & $\begin{array}{l}\text { Leptodactylus } \\
\text { macrosternum }\end{array}$ & Gosner Stages 28-30 & $\begin{array}{c}0.83 \\
16 \text { days }\end{array}$ & $\begin{array}{l}\text { Severe atrophy of thyroid gland. Significant size reduction and decrease in } \\
\text { the number of developmental stages (38-39). Acceleration of development. } \\
\text { Advanced snout ossification, and hypochord, medial fusion of girdles and } \\
\text { beginning of digestive tract transformation (vent tube and oral disc } \\
\text { disappearance and empty gut). }\end{array}$ \\
\hline & $\begin{array}{l}\text { Dermatonotus } \\
\text { muelleri }\end{array}$ & Gosner Stages 29-32 & $\begin{array}{c}0.83 \\
16 \text { days }\end{array}$ & $\begin{array}{l}\text { Severe atrophy of thyroid gland. Significant size reduction and decrease in } \\
\text { the number of developmental stages. Tail shortening and forelimb } \\
\text { emergence. Advanced snout ossification, and hypochord, medial fusion of } \\
\text { girdles and beginning of digestive tract transformation (vent tube and oral } \\
\text { disc disappearance and empty gut). Cartilages of skull and hyobranchial } \\
\text { apparatus remodel. }\end{array}$ \\
\hline
\end{tabular}




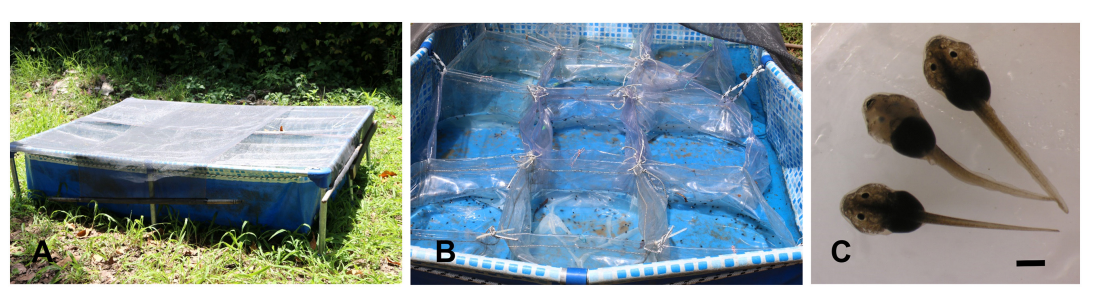

FIGURE 1 | (A) Containers with tadpoles were kept in two large receptacles, which were covered with a net to avoid bird predation. (B) Plastic containers (each one was identified with a label was assigned to a treatment) at the beginning of the experiments. (C) Tadpoles at Gosner Stage 25 . The scale bar is equals 1 mm.

and used as control, the remaining ones were assigned to two experiments (eight containers each): early exposure and late exposure.

Early exposure begins with the first dose of disruptor and tadpoles received a total of 15 doses of disruptor. From these treatments, a group of tadpoles from control and both treatments were collected and fixed after eight doses (18 days after hatching) to describe external morphology and identify larval stages. Early exposure finished 31 days after hatching and 29 days after the first dose of disruptor.

The late exposure experiment started 18 days after hatching and finished 31 days after hatching. Tadpoles of these treatments were at different stages of premetamorphosis, and received seven doses of disruptors during 13 days.

To perform the experiments, the concentrations of methimazole and T4 used by Fabrezi et al. (2019) were considered. Tables 1, 2 describe their results in anuran development using different concentrations of methimazole and T4, and starting exposure at developmental stages in which limb bud development is advanced. Based on those studies, we test lower concentrations of methimazole, and intermediate concentrations of T4 beginning earlier; and at similar stages but extending the experiments for more days.

For each exposure, four containers were supplied with $2.66 \mathrm{mg} / \mathrm{l}$ of methimazole every $48 \mathrm{~h}$, and four containers were supplied with $1.66 \mu \mathrm{g} / \mathrm{l}$ of T4 every $48 \mathrm{~h}$. Doses were dissolved in tap water. All the containers (a total of 20 treatments) were kept during 31 days after hatching when tadpoles were euthanized and fixed in $4 \%$ neutral buffered formaldehyde and Bouin's fixative for further analysis.

The formalin-fixed specimens for morphohistological studies, accessioned as lots, were deposited at the Instituto de Bio y Geociencias del NOA with the following collection numbers: IBIGEO-A 2301-00 (control tadpoles, January 11-29/2021); IBIGEO-A 2302-00 (control tadpoles: January 11-February 11/2021); IBIGEO-A 2303-00 (tadpoles from early methimazole exposure, January 13-29/2021); IBIGEOA 2304-00 (tadpoles from early T4 exposure, January 13-29/2021); IBIGEO-A 2305-00 (tadpoles from early methimazole exposure, January 11-February 11/2021); IBIGEO-A 2306-00 (tadpoles from early T4 exposure, January 11-February 11/2021); IBIGEO-A 2307-00 (tadpoles from late methimazole exposure, January 29-February); IBIGEO-A 2308-00 (tadpoles from late T4 exposure, January 29-February 11/2021).
Larval growth was inferred from changes in parameters of tadpole size: body length (i.e., the distance between snout and vent tube in ventral view) and total length (i.e., the distance between snout and tip of the tail in lateral view). Measurements were taken with dial calipers $(0.02 \mathrm{~mm})$ and are expressed in millimeters. Statistical analysis of body length and total length was based on non-parametric analysis of variance (KruskalWallis) test with multiple comparisons (InfoStat ${ }^{\circledR}$ v.2016).

Larval differentiation was documented based on morphological changes in external and internal morphology. Cleared and double-stained whole-mount specimens $(N=15)$ were used to examine musculoskeletal variation. Specimens were prepared using the technique of Wassersug (1976). Observations, descriptions, and illustrations were made with a Nikon-SMZ 1000 stereomicroscope equipped with a Nikon Coolpix digital camera. Furthermore, histological serial sections of $7 \mu \mathrm{m}$ thick of paraffin-embedded pelvis and hind limbs $(N=6)$ to describe skeleton tissues were stained with Masson's trichrome (Bancroft and Gamble, 2002) and observations were made with a Nikon E200 microscope equipped with a digital camera and Micro metrics SE Premium 4.5 software.

From six specimens fixed in Bouin's fixative, the buccal floor containing the hyobranchial apparatus with adhered thyroid lobes was manually dissected. The samples were dehydrated (by a series of ethanol solutions of increasing concentrations), embedded in paraffin, and sectioned at $5 \mu \mathrm{m}$ with a Leica RM 2245 rotatory semiautomatic microtome. Sections were stained with hematoxylin and eosin following the protocol of Martoja and Martoja-Pierson (1970). Photomicrographs were obtained with a Nikon E200 microscope equipped with a digital camera and Micro metrics SE Premium 4.5 software.

Histological descriptions and photomicrographs were taken from the widest cross-sectional area of the thyroid glands. Based on descriptions for other taxa (Etkin, 1936; Grim et al., 2009), we considered the following parameters: degree of follicular hypertrophy and hyperplasia, the height of follicular cells, presence of vacuoles in the colloid, and position and degree of condensation of the nuclei. The histomorphology of the thyroid gland was described at the end of experiment in tadpoles at larval Stage 40 (advanced prometamorphosis, Etkin, 1936).

All aspects of the research where approved by the Secretaría de Medio Ambiente y Desarrollo Sustentable, Gobierno de la Provincia de Salta, Argentina, and adhered to the legal requirements of Argentine laws (File number 227-216600/064/2016). 

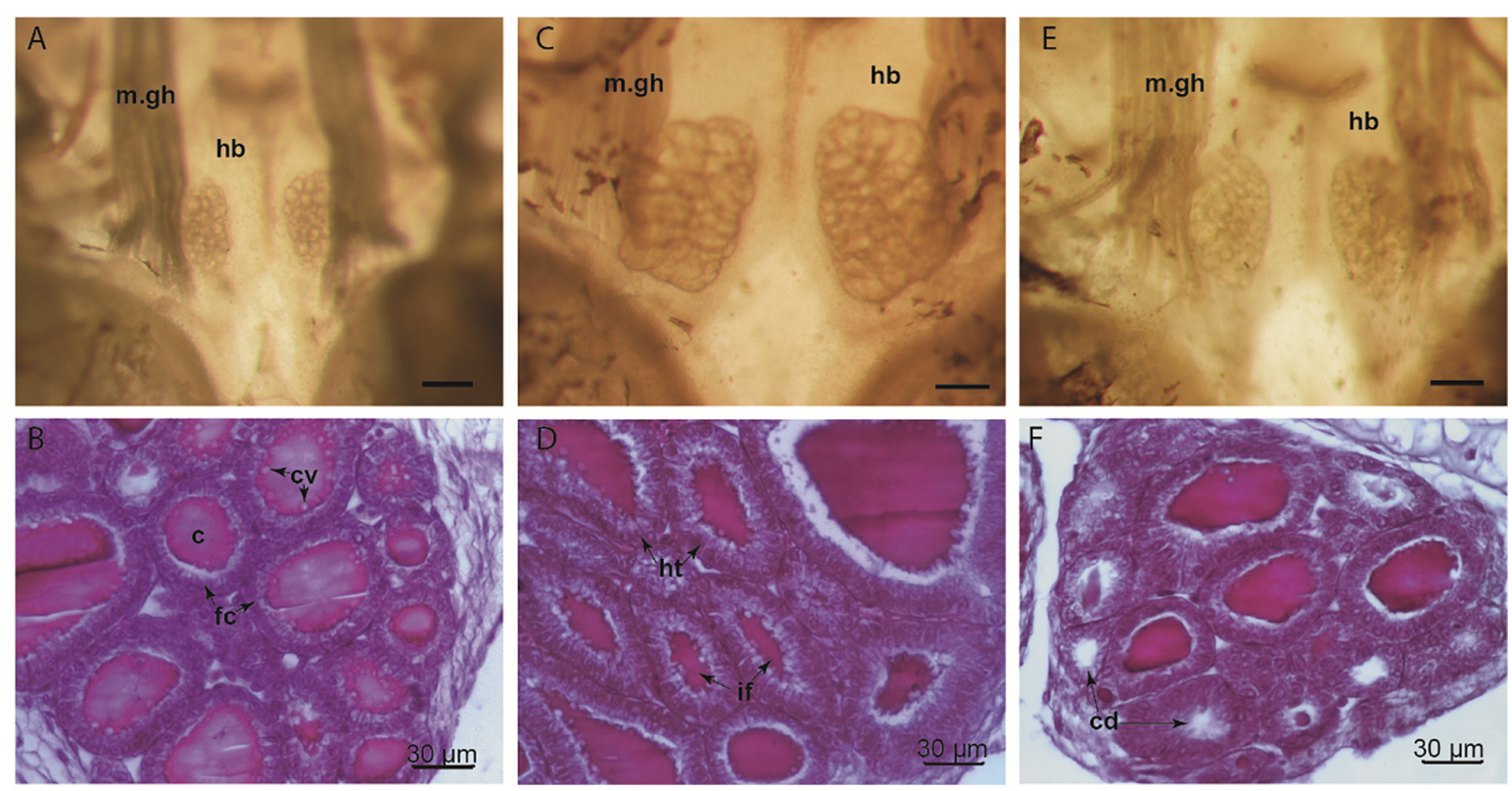

FIGURE 2 | Thyroid gland of Pleurodema borellii larvae (Gosner Stage 40, 31 days after hatching), macroscopic and microscopic images. (A,B) Control tadpoles showed the typical follicular morphology of the normal thyroid gland, with cuboidal follicular cells and follicular colloid. (C,D) Specimens from methimazole early exposure exhibited an overall glandular hypertrophy. The histology revealed an evident follicular cell hypertrophy and irregular follicular morphology. (E,F) Specimens from thyroxine early exposure have thyroid glands with follicular lumina less defined relative to the normal gland are also observed. Histological section shows slight depletion of colloid and decrease in the number of chromophobic vacuoles. c, colloid; cd, colloid depletion; cv, chromophobic vacuoles; fc, follicular cells; hb, hypobranchial cartilage; ht, hyperthrophied cells; if, irregular follicles; m.gh, muscle geniohyoideus. Scale bar for macroscopic images = 0.3 mm.

\section{RESULTS}

\section{Effects of Disruptors on the Thyroid Gland}

The histomorphology of the thyroid gland in advanced prometamorphosis at the end of experiments of early exposure were analyzed. We selected specimens in similar developmental stage (Gosner Stage 40) in order to describe the thyroid gland on the threshold of metamorphosis (Figure 2). Cruz (2020) described in Pleurodema tadpoles, the follicular number, the colloid volume and the height of the follicular epithelium with their maximum values among Gosner Stages 39-44, reaching the peak between stages 41-42 and concomitant with the maximum volume of the gland.

A considerable increase in overall thyroid gland size was observed in the specimens exposed to methimazole, the glandular lobes were larger with respect to the control specimens, indicating glandular hypertrophy (Figure 2). In addition, numerous thyroid follicles exhibiting abnormal morphology (mostly large follicles with colloid content) were observed. The presence of blood cells in interfollicular gaps was greater than in the untreated glands. Follicular cells ranged from tall cubic to columnar, and mild cellular hyperplasia was observed in some follicles. A slight decrease in the number of chromophobic vacuoles was observed inside the colloid.

The thyroid gland of specimens exposed to thyroxine showed slight glandular atrophy relative to untreated specimens. Some heterogeneity in the size of lobes and follicles was observed
(Figure 2). A large proportion of small follicles was observed, with no colloid content. Only a few larger follicles had colloid content. There were no considerable differences in the height of the follicular cells (Figure 2). However, a decrease in the amount of chromophobic vacuoles present inside the colloid was observed with respect to the control specimens.

\section{Growth Rates}

Methimazole exposure caused significant differences in growth (Figure 3, 4 and Table 3). Early exposure showed the increment of body length and total length when tadpoles were evaluated 18 days after hatching and at the end of experiments. Late exposure also produces significant increment of growth. The variability between maximum and minimum values of body size and total length in early treated tadpoles was greater than that of late-treated tadpoles.

T4 exposure altered growth rates (Figure 3, 4 and Table 3). Early exposure showed the increment of body length and total length when tadpoles were evaluated 18 days after hatching, but at the end of experiments only total length is significantly different from controls. Late exposure also produces significant increment of growth. The variability between maximum and minimum values of body size and total length in T4-treated tadpoles is minor to the controls.

\section{Rates of Differentiation}

Tadpoles treated early with methimazole were in premetamorphic larval stages (i.e., Gosner Stages 28 and 36) 
A

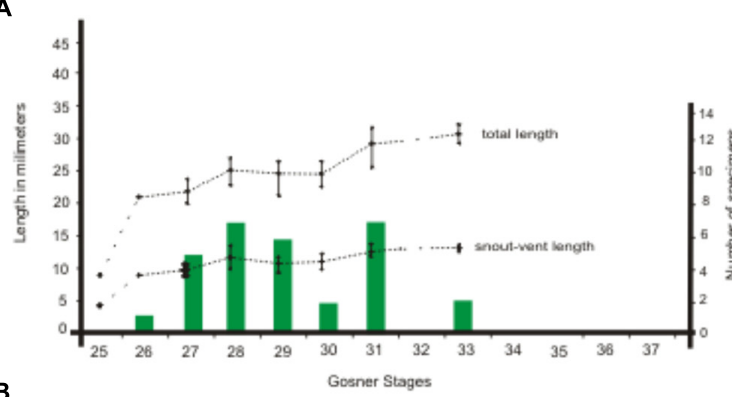

B

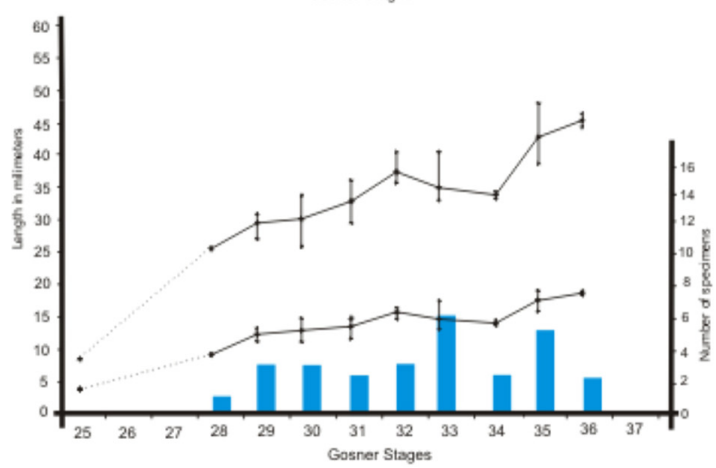

c

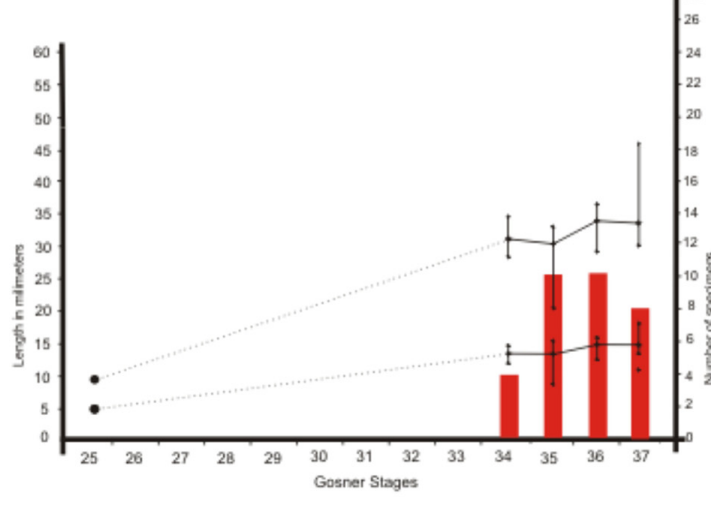

E

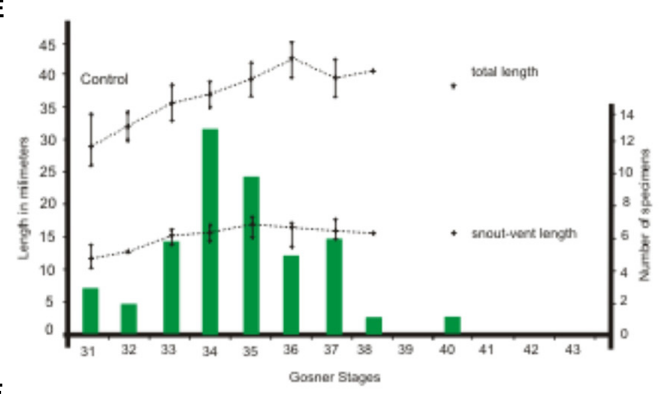

F

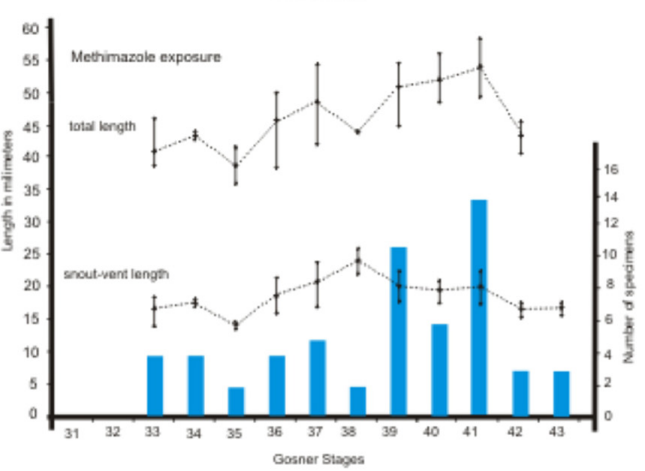

G

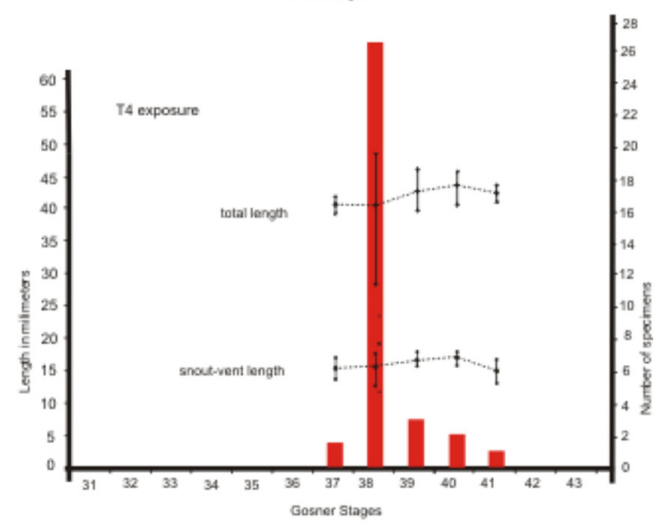

H

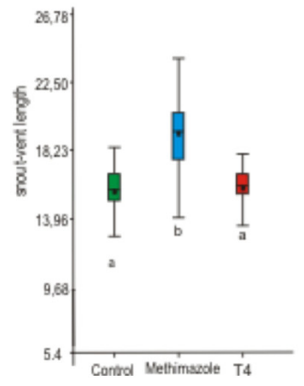

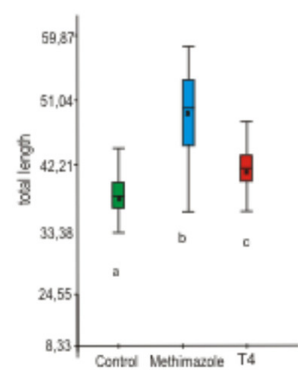

FIGURE 3 | Pleurodema borellii size variation of each larval stage exposed early to methimazole and T4. (A-D) The experiment began with tadpoles in Gosner Stage $25(N=7)$, with an average snout-vent length of $3.30 \mathrm{~mm}( \pm 0.35)$ and an average total length of $8.07 \mathrm{~mm}( \pm 0.19)$. Snout-vent length and total length of each larval stage (bars) after 18 days after hatching were measured to determine growth. Simultaneously, tadpoles were also staged. (A) Control specimens. (B) Tadpoles exposed to methimazole (eigth doses). (C) Tadpoles exposed to T4 (eigth doses). (D) Significant differences were found in size variables $(p<0.05$ for snout-vent length and total length) between each treatment and the control. (E-H) Continuity of treatments up to 31 days after hatching (a total of 15 doses). Snout-vent length and total length of each larval stage (bars) at the end of experiments were measured and tadpoles were staged. (E) Control specimens. (F) Tadpoles exposed to methimazole (15 doses). (G) Tadpoles exposed to T4 (15 doses). (H) Significant differences were found in size variables $(p<0.05$ for snout-vent length and total length) between each treatment and the control.

18 days after hatching and reached prometamorphic stages and even metamorphic stages, but some remained at premetamorphic stages (i.e., Gosner Stages 35 and 36) at the end of experiment
(31 days after hatching). Early exposure to methimazole accelerated the differentiation respect to the control, although the responses were variable since tadpoles range among 
TABLE 3 | Descriptive statistics for snout-vent length (SVL) and total length (TL) of Pleurodema borellii during larval stages comprising pre and prometamorphic stages with exposure to methimazole or T4.

\begin{tabular}{|c|c|c|c|c|c|}
\hline $\begin{array}{l}\text { Beginnig of } \\
\text { experiments }\end{array}$ & End of exposure & Specimens & $\mathbf{N}$ & Mean SVL \pm SD $(\mathrm{mm})$ & Mean TL \pm SD $(\mathrm{mm})$ \\
\hline Early exposure & 18 days after hatching & Control & 26 & $10.98 \pm 1.58(\mathrm{a})$ & $26.17 \pm 3.68(a)$ \\
\hline \multirow[t]{5}{*}{2 days after hatching } & & Methimazole & 27 & $13.98 \pm 2.36(b)$ & $33.56 \pm 5.67(b)$ \\
\hline & & Thyroxine & 32 & $12.55 \pm 1.58(\mathrm{c})$ & $29.95 \pm 3.99$ (c) \\
\hline & 31 days after hatching & Control & 47 & $15.63 \pm 1.66(\mathrm{a})$ & $37.62 \pm 3.70(a)$ \\
\hline & & Methimazole & 57 & $19.31 \pm 2.41(\mathrm{a})$ & $49.17 \pm 5.73(b)$ \\
\hline & & Thiroxine & 45 & $15.89 \pm 1.26(b)$ & $41.24 \pm 3.47$ (c) \\
\hline Late exposure & 31 days after hatching & Control & 47 & $15.63 \pm 1.66(\mathrm{a})$ & $37.62 \pm 3.70(a)$ \\
\hline \multirow[t]{2}{*}{18 days after hatching } & & Methimazole & 56 & $16.84 \pm 1.58(b)$ & $43.01 \pm 4.36(b)$ \\
\hline & & Thiroxine & 59 & $16.59 \pm 1.16(b)$ & $42.86 \pm 3.37(b)$ \\
\hline
\end{tabular}

Mean lengths with different letter symbols in parenthesis are significantly different from each other $(P<0.0001)$, as determined by Kruskal Wallis test.

premetamorphic, prometamorphic and metamorphic stages (Figures 3, 5). Tadpoles under late exposure were at advanced premetamorphic stages or early prometamorphic stages (i.e., Gosner Stages 31-37) without reaching metamorphic stages 31 days after hatching (Figures 4, 5).

Early T4 exposure accelerated differentiation and reduced the number of the stages of development (Figures 3, 5). When tadpoles were evaluated 18 days after hatching, most tadpoles were in later premetamorphic stages and earlier prometamorphic stages (four stages). Tadpoles at the end of experiment (31 days after hatching) were in prometamorphic stages (i.e., Gosner Stages 37-40). Tadpoles under late exposure to T4 reached prometamorphic stages (i.e., Gosner Stages 38-41) and metamorphic stages (Figures 4, 5).

\section{Skull Skeleton Differentiation}

In tadpoles exposed (early and late exposures) to methimazole and T4, specimens in prometamorphic stages show the differentiation of the nasal cartilages and the appearance of snout bones (nasal, septomaxillary, premaxillary) emerged in the sequences described for most anurans (Trueb, 1993; Fabrezi, 2011), without differences between disruptors (Figure 6).

\section{Abnormalities}

At the end of experiments, we recorded abnormalities identified as an unusual morphology of the anal tube and hind limb asymmetry (Figure 7 ). The proportion of abnormalities was higher in those specimens under T4 exposures (95\% early exposure and $75 \%$ late exposure) and near 50\% in both treatments under methimazole (Figure 4).

The asymmetry of the hind limbs seems to be related to the incomplete development of the acetabulum; thus, the femur does not articulate with the pelvis but is suspended from the pelvis by soft tissues (Figures 8, 9). In the pelvis, the elongation of the ilium is different in each hemigirdle, and in some cases, there is no elongation (Figure 8).

The development of the ventral elements of the pectoral girdle is also abnormal in specimens exposed to disruptors, although the glenoid cavity appears well defined and the humerus is articulated (Figure 8). In each half of the pectoral girdle, the procoracoids, coracoids, and epicoracoids have an asymmetric development and there is a delay in the endochondral ossification of the coracoid and in the differentiation of the clavicle.

The muscles iliacus externus, and tensor fasciae latae have origins on the iliac shaft and insert on the femur. The pattern described for Pleurodema borellii (Fabrezi et al., 2014) is observed in control tadpoles at Gosner Stage 38 (Figure 8). In specimens exposed to methimazole (early exposure) at similar stages, the muscle iliacus externus is shorter and compact and the tensor fasciae latae is formed by loose fibers (Figure 8). In specimens exposed to T4 (early and late exposures), few and loose fibers of the muscle iliacus externus are attached to the short ilium when it is present (Figure 8) or not when the cartilaginous iliac shaft is absent (Figure 8).

Histological sections (Figure 9) of specimens treated with methimazole revealed: malformed pelvic cartilages, absence of the acetabulum, and disorganized fibers in those muscles with attachments on the pelvis (Figure 9). The pelvis is amorphous and rudimentary, and the absence of acetabulum precludes the hind limb articulation. Numerous chondroblasts and reduced extracellular matrix constitute the pelvis and the proximal epiphysis of the femur (Figure 9). The histology of the pelvis and femurs of specimens treated with T4 showed similar chondrogenesis to that observed in controls, the hypertrophy of chondrocytes increases toward the middle of diaphysis (Figure 9). However, T4 exposure affected processes that model and shape the cartilages and the absence of acetabulum prevents the femur joint.

\section{DISCUSSION}

\section{Effects of Disruptors on the Thyroid Gland}

The effects of methimazole and T4 on TH synthesis and larval development are well known from experiments involving the model species Xenopus laevis. Some generalizations emerged from those studies: they described the concentrations at 


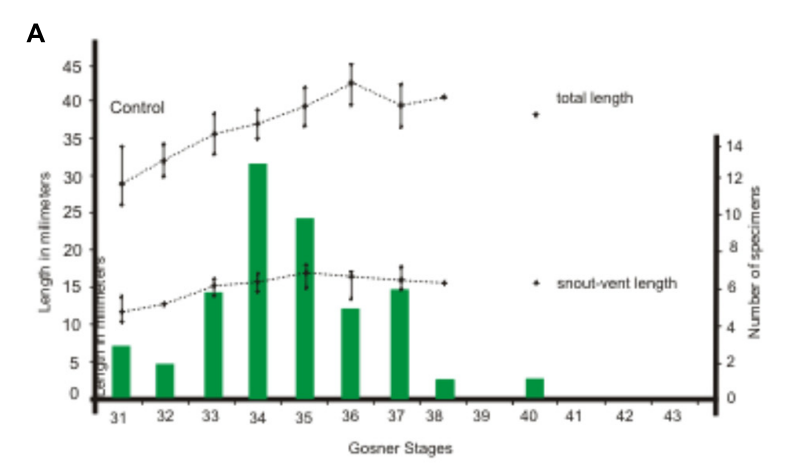

B

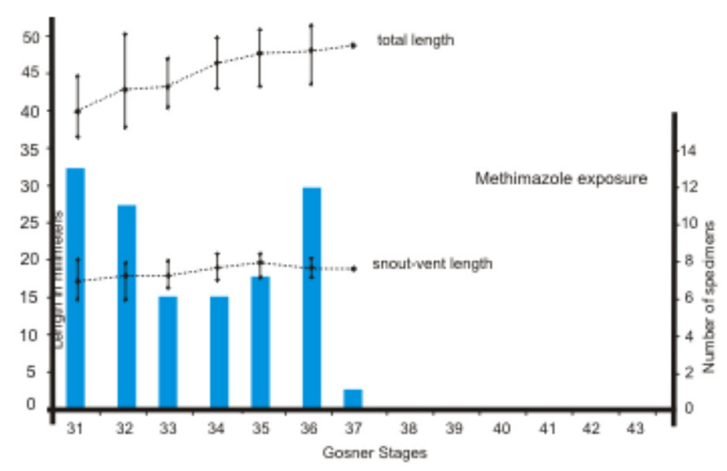

C

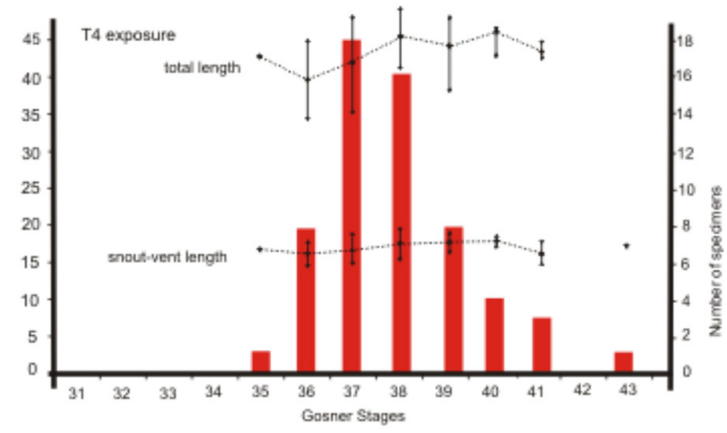

D

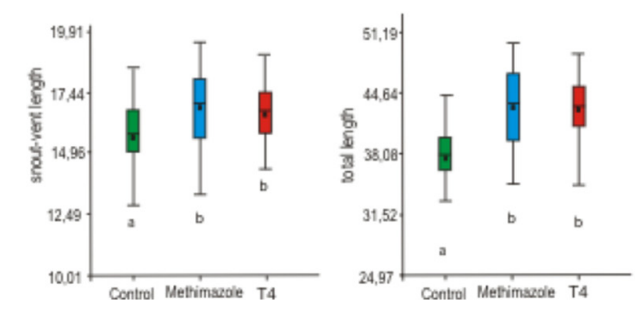

FIGURE 4 | Variation in size of each larval stage of Pleurodema borellii during late exposure to methimazole and T4. (A-D) The experiment began at 18 after hatching. Tadpoles were exposed for 13 days (seven doses). (A) Control specimens. (B) Tadpoles exposed to methimazole. (C) Tadpoles exposed to T4. (D) Significant differences were found in size variables $(p<0.05$ for snout-vent length and total length) between each treatment and the control. However, no significant differences were found among size variables between tadpoles exposed to methimazole and tadpoles exposed to T4.

which these disruptors cause hypertrophy or atrophy of the thyroid gland, the effects of early or late exposure on development rates, and the consequences of the duration of exposure on sensitivity (Degitz et al., 2005; Opitz et al., 2006; Grim et al., 2009; Smirnov and Vassilieva, 2014; among others). In this study, continuous exposure to low concentration of methimazole and intermediate concentration of T4 for 31 days after hatching in Pleurodema borellii produced moderated changes in the thyroid gland histology.

In Xenopus laevis (Degitz et al., 2005), the severity of thyroid gland hypertrophy caused by methimazole depends on the concentration, although the minimal concentrations used in those experiments were higher $(6.25 \mathrm{mg} / \mathrm{l})$ and the period of exposure was shorter than in our treatments (Table 1). Fabrezi et al. (2019) found moderate hypertrophy of the thyroid gland with increment of growth in Pleurodema borellii and Leptodactylus chaquensis using a similar concentration of methimazole $(6.6 \mathrm{mg} / \mathrm{l})$ to those used in experiments of $X$. laevis (Degitz et al., 2005) and 10 and 16 days of exposure, respectively (Table 1). Here, we tested a lower concentration of methimazole (2.66 $\mathrm{mg} / \mathrm{l})$ starting the exposure in earlier larval stages (early exposure) for more days and we found the expected thyroid gland hypertrophy.

The severity of thyroid gland atrophy caused by T4 depends on the concentration, ranging from 0.25 to $4 \mu \mathrm{g} / \mathrm{l}$, and the period of exposure (Series numbers 76 and 77-) $)^{1}$ in Xenopus laevis. A low concentration of T4 $(0.83 \mu \mathrm{g} / \mathrm{l})$ caused mild atrophy of the thyroid gland at 10 days of exposure in Pleurodema borellii and severe atrophy at 16 days of exposure in Leptodactylus chaquensis and Dermatonotus muelleri (Fabrezi et al., 2019). Furthermore, L. chaquensis and D. muelleri showed a notable acceleration of differentiation but not of growth, revealing interspecific differential responsiveness and sensitivity of different tissues to specific hormonal signals. In this study, the effects of medium concentrations $(1.66 \mu \mathrm{g} / \mathrm{l})$ of T4 on the thyroid gland of Pleurodema borellii were moderate despite differences in concentrations and days of exposure with the former experiments. Prolonged exposure to T4 may reduce sensitivity, as recorded in Xenopus laevis (Degitz et al., 2005).

\section{Changes in Growth and Differentiation Rates}

Under natural conditions, Pleurodema borellii growth is accelerated at the beginning of larval development (between Gosner Stages 25-30) and then it continues with a moderate increase up to the beginning of metamorphosis. Larval development shows strong heterochronies, since after 20 days of development some tadpoles are in stages of the limb bud and others are reaching the end of premetamorphic stages. Larval development takes 60 days on average (Cruz, 2020).

Acceleration in growth -which was remarkable in prometamorphic larval stages-was observed when tadpoles were exposed early to methimazole (Figures 3-5). Furthermore, methimazole did not delay differentiation or inhibit metamorphosis; on the contrary, it was observed

\footnotetext{
${ }^{1}$ http://www.oecd.org/env/ehs/testing/seriesontestingandassessmentecotoxicity testing.htm
} 


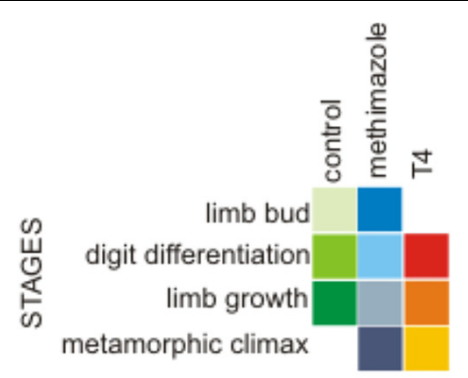

A

\section{A}

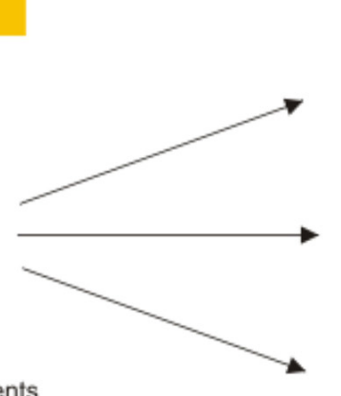

symmetrical hind limbs

asymmetrical hind limbs
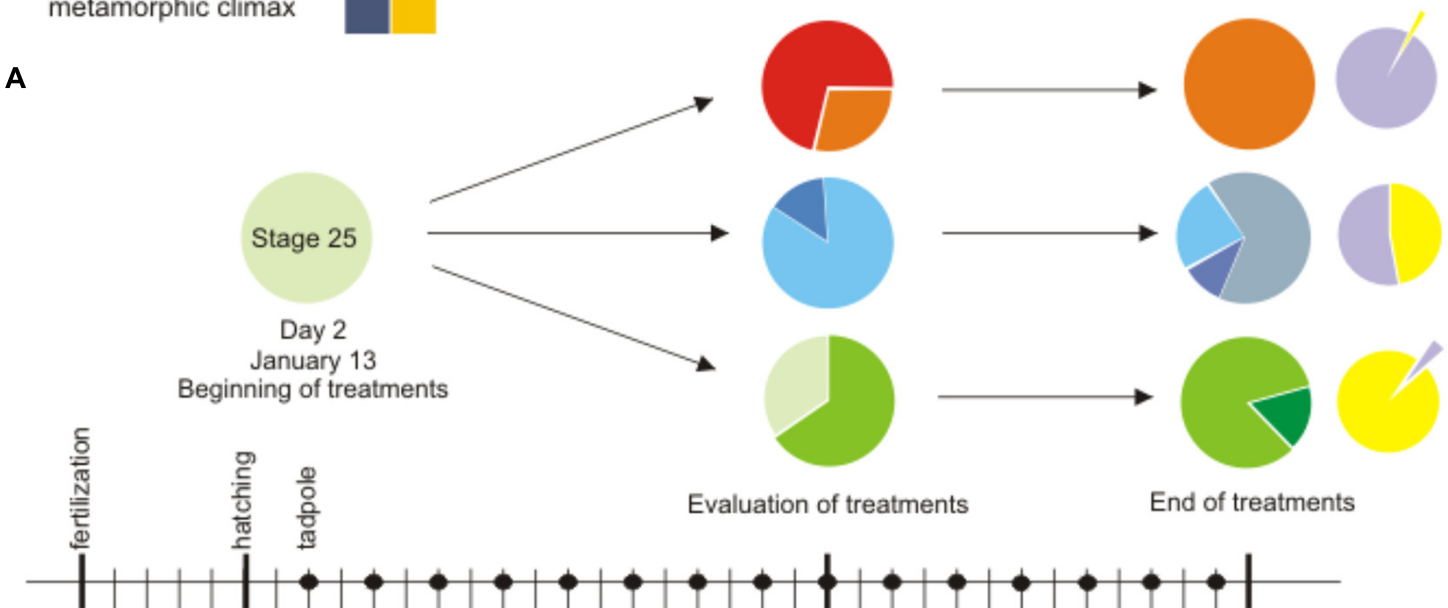

Evaluation of treatments

End of treatments

January 6 Day 0

January 11

Day 18

January 29

Day 31

February 11

\section{B}

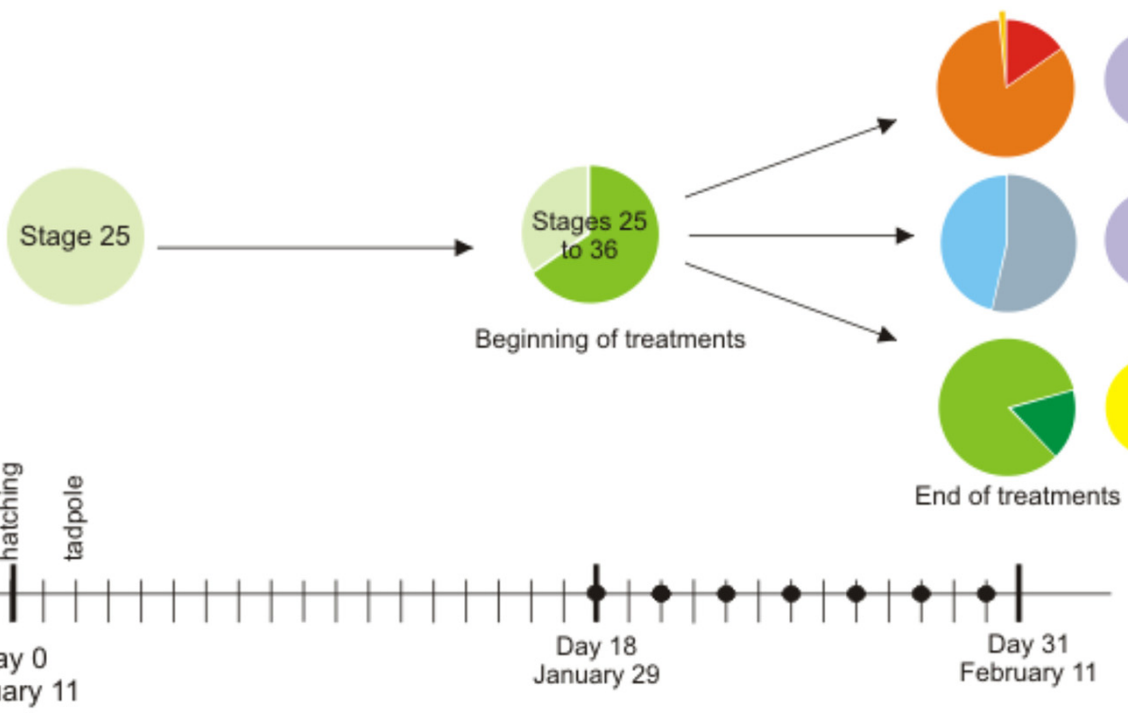

FIGURE 5 | Proportion of differentiation stages of tadpoles during the experiments: premetamorphosis [limb bud stages (Gosner 25-30) and digit differentiation (Gosner 31-36)], prometamorphosis [limb growth (37-41)] and metamorphic climax (42-46) and proportion of abnormalities (identified as hind limbs asymmetries in violet, and normal in yellow) at the end of experiments. (A) Early exposure: control in green circles ( $N=28$ at 18 days after hatching; $N=60$ at 31 days after hatching) with one specimen with abnormal limbs (violet); methimazole in blue circles ( $N=27$ at 18 days after hatching, $N=47$ at 31 days after hatching), abnormalities appear in the half of tadpoles; and T4 in red and orange circles ( $N=28$ at 16 days of exposure, $N=61$ at 29 days of exposure), almost all tadpoles present abnormalities (violet) (B) Late exposure: control in green circles ( $N=60$ at 31 days after hatching), methimazole in blue circles ( $N=47$ after 14 days of exposure), abnormalities appear in the half of tadpoles, and T4 in red-orange circles ( $N=61$ after 14 days of exposure), abnormalities appear in $75 \%$ of tadpoles. Black dots indicate doses. 

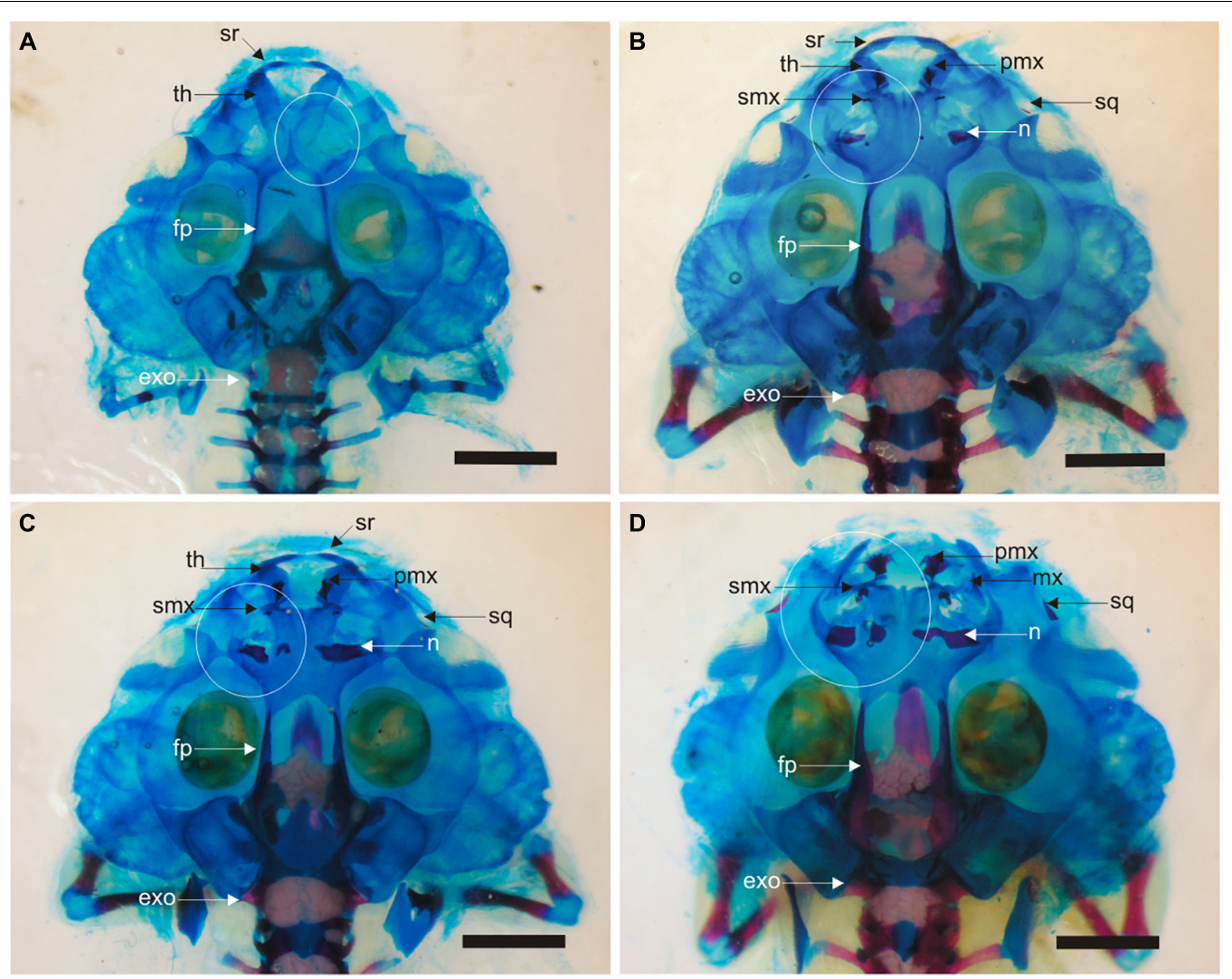

FIGURE 6 | Skull skeleton in tadpoles after 31 days of larval development. (A) Control specimen at Gosner Stage 38. Incipient development of cartilages of olfactory capsule denoted by the white circumference. The ossification of frontoparietals and parasphenoid are already present. Accumulation of calcium is observed in the braincase. (B) Specimen of early exposure to T4 (Gosner Stage 40). Dorsal cartilages of the olfactory region and dermal ossifications (nasals, premaxillae, maxillae, septomaxillae, and squamosals) have differentiated and erosion of trabecular horns has started. Frontoparietals, parasphenoid and exoccipitals are advanced. Accumulation of calcium is observed in the braincase and vertebral column. (C) Specimen of early exposure to methimazole (Gosner Stage 40); same as the specimen described in (B). (D) Specimen of early exposure to methimazole (Gosner Stage 41). Erosion of larval structures (suprarostral cartilage and trabecular horns) is advanced. exo, exoccipital; fp, frontoparietal; mx, maxillary; n, nasal; pmx, premaxillary; smx, septomaxillary; sq, squamosal; sr, suprarostral; th, trabecular horn. Scale bar is equal $2 \mathrm{~mm}$.

individual differences, with some tadpoles reaching metamorphosis while others have just reached premetamorphic states. Phuge et al. (2021) reported the ethylenethiourea (a thyroid inhibitor) did not affect metamorphosis in Sphaerotheca pashchima and at lower concentrations stimulated metamorphosis in the anuran Indosylvirana caesari, and suggested differences in the larval development duration and sensitivity. Our experiments revealed that the stage at which exposure started had an impact on larval differentiation, since tadpoles exposed earlier to methimazole reached metamorphosis whereas tadpoles exposed later remain in prometamorphosis. Then, the effects of disruptor at limb bud stages (i.e., Gosner Stages 25-29) may trigger acceleration of growth and changes in differentiation rates, resulting in the increment of developmental variability and stimulating metamorphosis.

Early exposure to T4 also caused significant variation in growth increase; however, the curve shows a deceleration and reduction of growth variability when prometamorphic stages were reached after 18 days after hatching (Figure 3). Early and late T4 exposures also accelerated differentiation, with most tadpoles reaching prometamorphosis after 31 days after hatching. Reduction in the variability of development is noticeable, since the controls spanned nine developmental stages (31-40), whereas tadpoles exposed early to T4 spanned five stages (37-41) at the end of experiments.

Under wild conditions, sustained growth over time is associated with a temperate climate and/or permanent ponds, which provide good environmental conditions to ensure metamorphosis (Emerson, 1988; Roček et al., 2006) or the spontaneous absence of thyroid glands that preclude metamorphosis (Rot-Nikcevic and Wassersug, 2003, 2004). In turn, rapid development is related to unpredictable environmental conditions, in which an abundance of resources suggests that increased protein in the diet enhances either growth or differentiation (Kupferberg, 1997). In P. borellii, exposure to methimazole produces variation that resembles the larval development of those species with high developmental variability, like Pseudis platensis (Fabrezi et al., 2009; Fabrezi, 2011; Cruz and Fabrezi, 2019), whereas early T4 exposure 


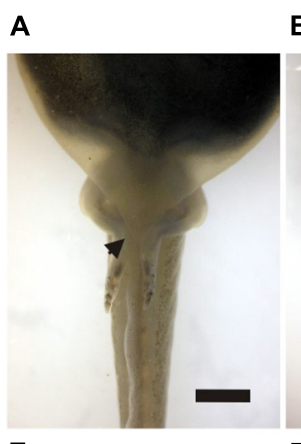

E
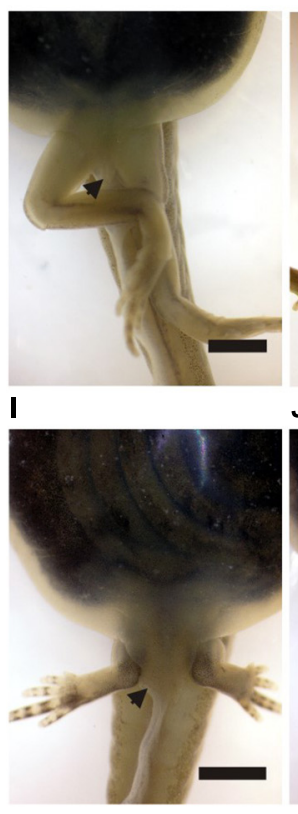

B

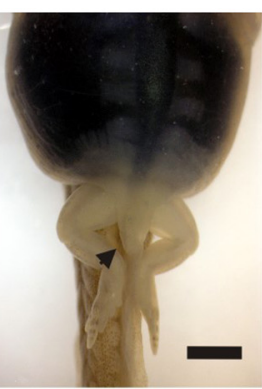

F

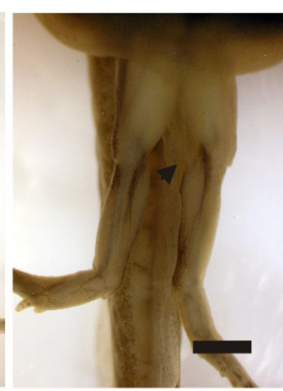

J

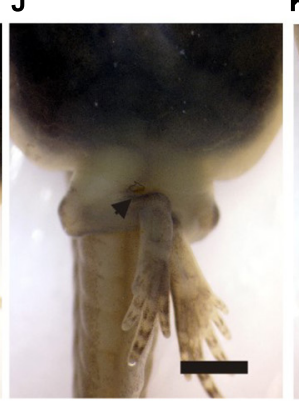

C

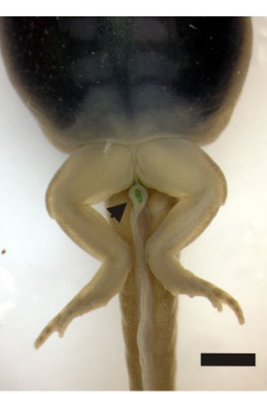

G

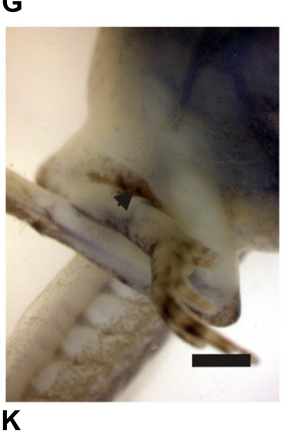

D

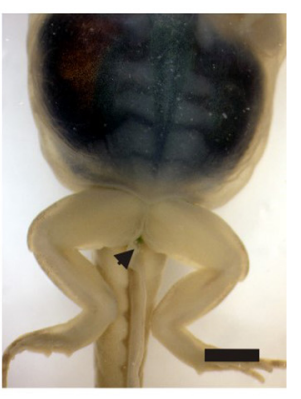

H

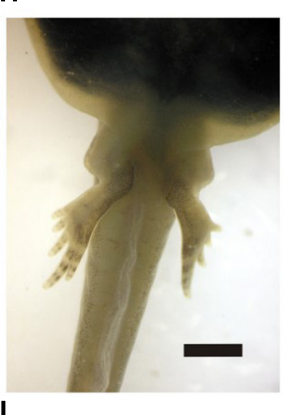

L

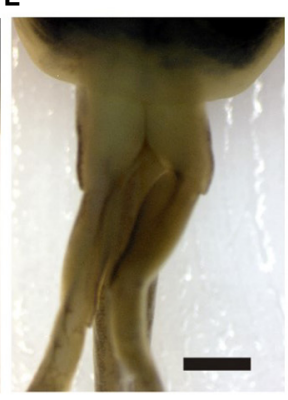

FIGURE 7 | (A-D) Sequence of disappearance of vent tube in Pleurodema borellii in normal development observed in Gosner Stages 37, 39, 40, and 41. (E-H) Different morphologies of vent tube and asymmetry of legs in specimens exposed to methimazole. (I-L) Different morphologies of vent tube and asymmetry of legs in specimens exposed to T4. Scale bar is equal $2 \mathrm{~mm}$.

reduces variation like the larval development of those species that develop rapidly before the pond dries (Fabrezi, 2011; Fabrezi and Cruz, 2014). Furthermore, similar growth and differentiation rates in sister tadpoles forming schools are typical of some species of genus Leptodactylus (de Sá et al., 2014). The role of $\mathrm{T} 4$ to reduce the variability in larval development was also observed in Leptodactylus macrosternum (Fabrezi et al., 2019).

\section{Skull Skeleton Differentiation}

Tadpoles exposed at very low or intermediate concentrations of methimazole and T4, respectively, showed internal changes concomitant with the stages reached. Differentiation of the cartilaginous skeleton of olfactory capsules and of bones of the rostral region, and resorption of larval cartilages (suprarostral and trabecular horns) follow the sequence described for most species (Trueb, 1993; Fabrezi, 2011). By contrast, tadpoles of Dermatonotus muelleri exposed to lower concentrations of T4 revealed cartilaginous skull remodeling among other metamorphic features even when hind limb development indicated Gosner Stages 38-39 (Table 2; Fabrezi et al., 2019).

Rose and Cahill (2019) used thyroid gland inhibitors to isolate the effects of T3 and T4 at specific concentrations, and described changes in growth and differentiation of cranial cartilages during larval development of Xenopus laevis. They found differences in the timing in which T4 (earlier) and T3 (later) induced remodeling; absence of dose-dependent responses among stages, and differences of morphological changes when thyroid gland inhibitors were applied. Our results revealed weak inhibition of the thyroid gland activity and supplementation of T4 did not affect sequences of skull bone differentiation.

\section{Abnormalities}

Externally, abnormal morphogenesis is observed as an asymmetry of the hind limbs, linear arrangement of the limb segments, and the modification of the vent tube. The combination of these altered morphologies was observed in two control specimens $(N=61)$, the half of specimens under 

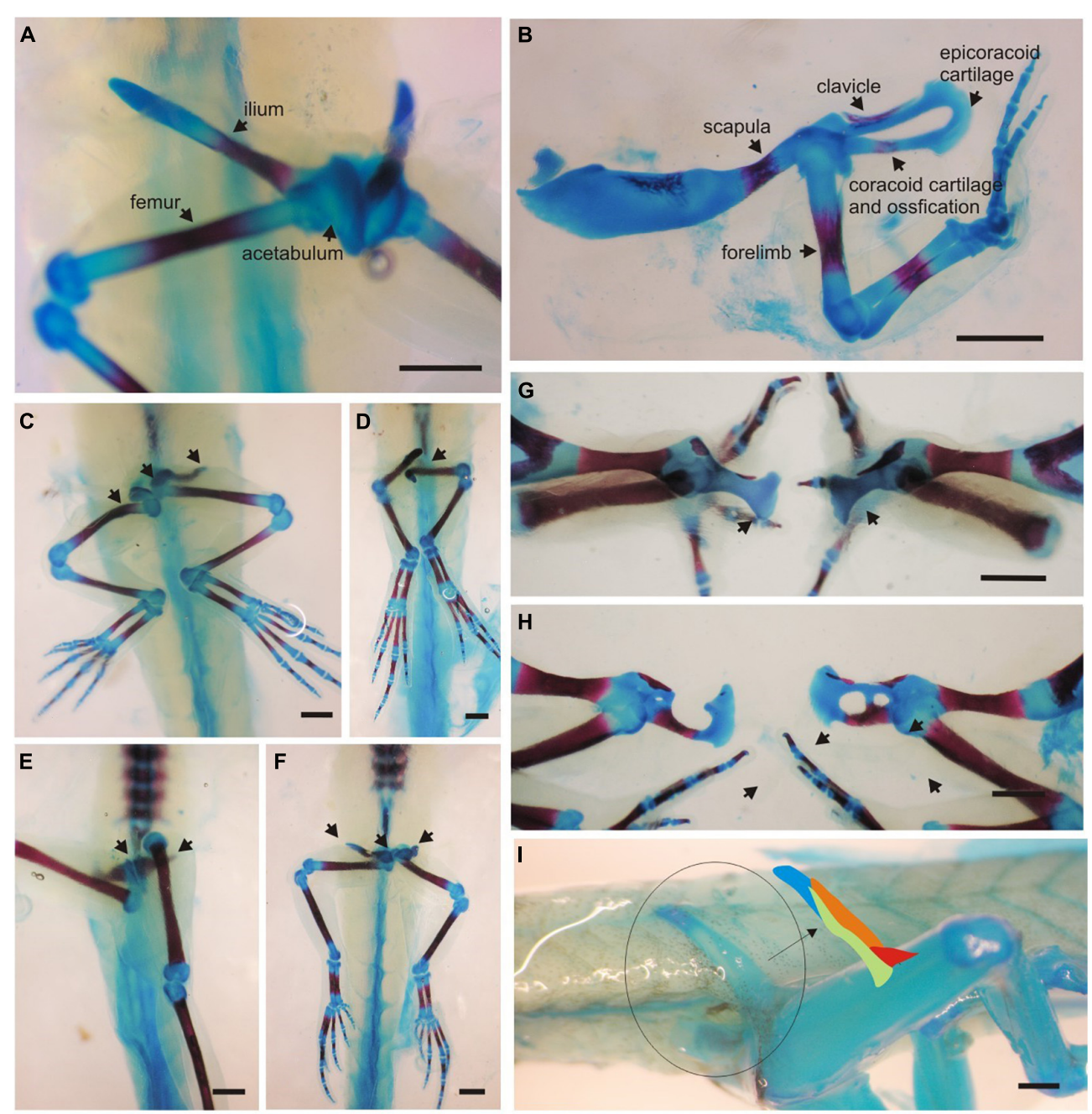

$\mathbf{F}$
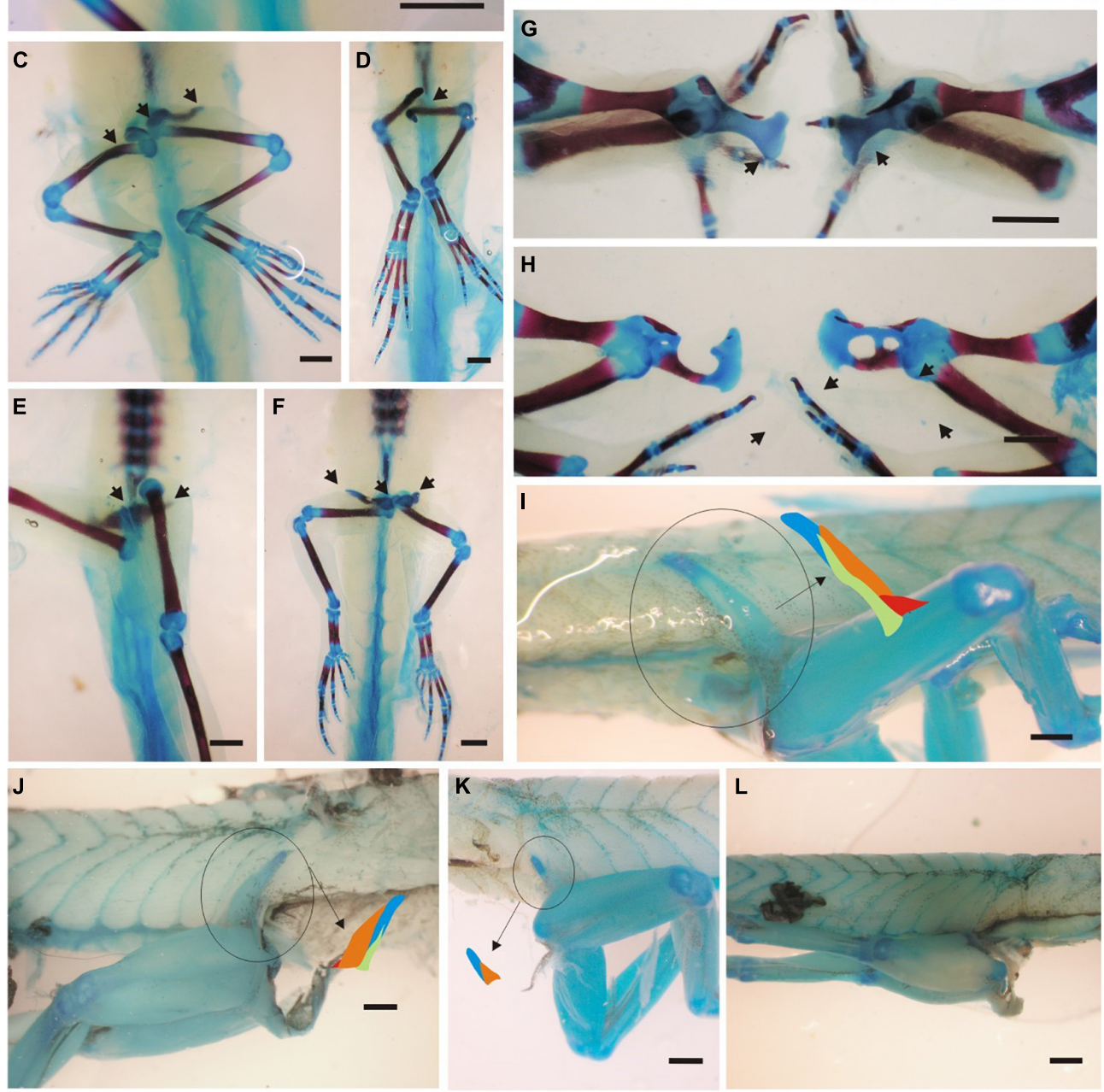

FIGURE 8 | Abnormalities in girdles and limb skeletons and muscles. (A) Ventral view of the pelvis in a control specimen (Gosner Stage 40). (B) Right pectoral girdle and forelimb in a control specimen (Gosner Stage 40). (C,D,G) Girdle and limb skeleton in specimens exposed to methimazole at the end of experiments. (C) Femurs hung from rudiments of pelvis, right femur is curved, and the ilion is short. (D) Underdevelopment of pelvis and hind limbs joined by soft tissues to hypaxial muscles. (G) The coracoid cartilage is present but the procoracoid and the ossification of clavicle are defective. (E,F,H) Girdle and limb skeleton in specimens exposed to T4 at the end of experiments. (E,F) In both specimens the acetabulum is not well formed and the ilium is short. (H) The cartilaginous elements of each half of the girdle (coracoid, procoracoid and epicoracoid) show unequal differentiation and growth. (I) Lateral view of pelvis muscles (pelvis to femur) in control specimen at the end of experiment (Gosner Stage 38). The iliac shaft reached the limit between hypaxial and epaxial musculature. The schematic representation described the organization of three pelvic muscles: the muscle iliacus internus (red) originated at the basis of the ilium (blue) and inserted on the femur; the muscle iliacus externus (orange) attached along the anterior half of the iliac shaft and the tensor fasciae latae (green) from the laterointernal surface of the ilium to the thigh. This pattern is observed in the adult of Pleurodema borellii (Fabrezi et al., 2014). (J) Specimen under early exposure to methimazole after 31 days of larval development (Gosner Stage 38). The iliac shaft reaches the inferior half of hypaxial musculature and the muscles are also short. The tensor fasciae latae have loose fibers. (K,L) Specimens (Gosner Stage 38) under early exposure to T4 at the end of experiments. (K) The underdevelopment of the short iliac shaft is complemented with a short muscle iliacus externus. (L) The specimen without pelvic girdle and absence of pelvic muscles. The thigh is attached by soft connective fibers to hypaxial muscles as is observed in detail in (K). Bar is equal to $1 \mathrm{~mm}$. 


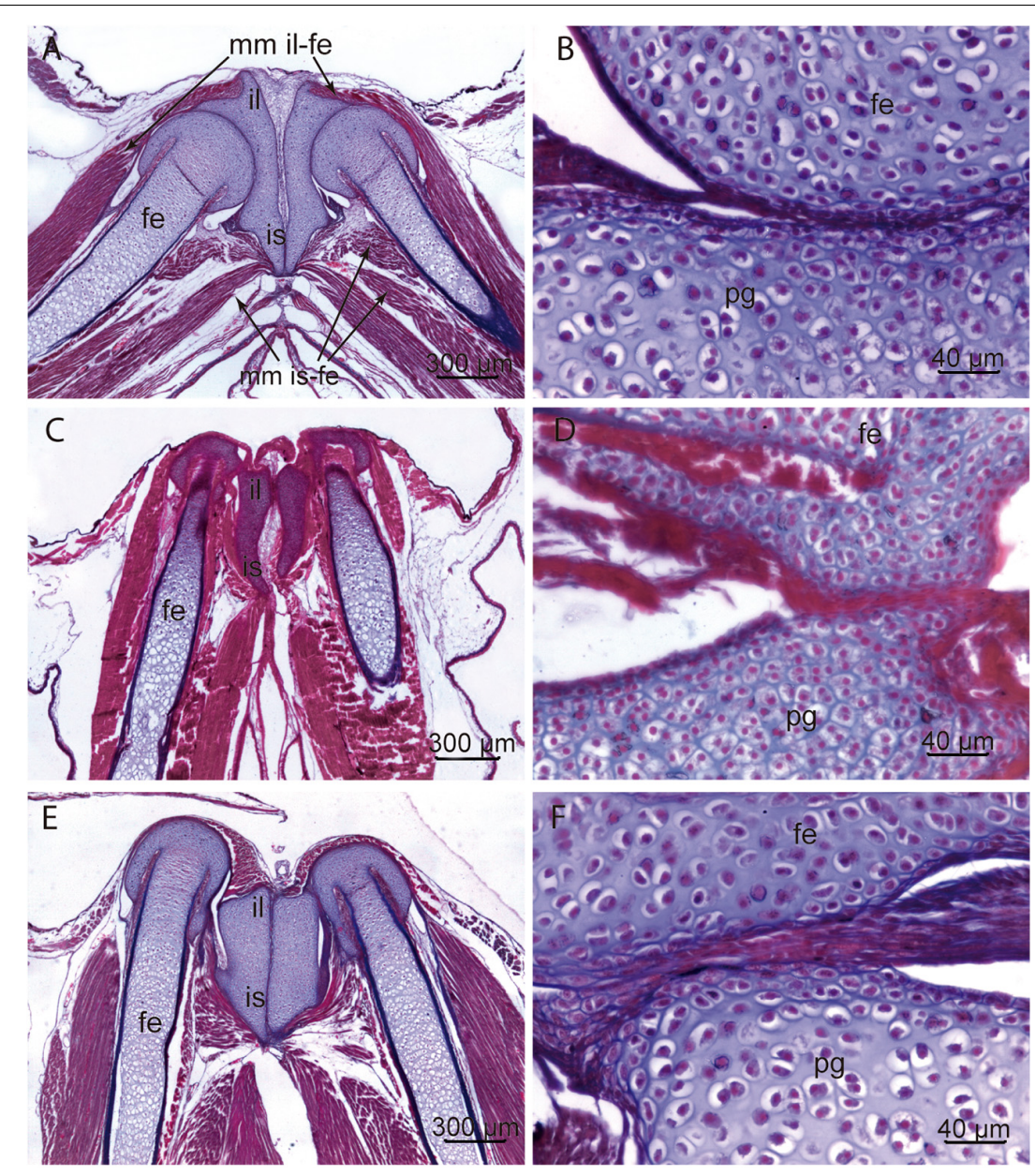

FIGURE 9 | Histology of pelvic girdles. (A,B) Control specimen (Gosner Stage 39). Section of the ilium-ischium cartilage. Each hemigirdle contacts with the opposite at the mid-ventral line. Epiphyses of the femur are well defined and fit in the acetabulum. The diaphysis of the femur is formed by hyaline cartilage with hypertrophic chondrocytes and incipient perichondral ossification. The epiphysis of the femur and the pelvic cartilage present abundant chondroblasts rounded by extracellular matrix. The organization of the thigh musculature is advanced. (C,D) Methimazole treated specimen (Gosner Stage 39). The rudimentary differentiation of femoral epiphyses and pelvic girdle indicates a delayed local development with the proliferation of chondroblasts, concomitant with a scarce extracellular matrix. The atrophy of muscles attached to the ilium, ischium, and proximal segment of the femur is evident. (E,F) Specimen exposed to T4 (Gosner Stage 39). The asymmetry of ilium-ischium cartilage and the absence of acetabulum precludes the articulation of hind limb. The asymmetry is also observed in the associated muscles. The histology of cartilage shows a pattern of chondrogenesis similar to control specimens. fe, femur; il ilium; is, ischium; mm il-fe, muscles originated in the ilium and inserted on the femur muscles; mm is-fe, muscles originated in the ischium and inserted on the femur; pg, pelvic girdle.

methimazole exposures, and almost all T4 specimens from early exposure and the 75\% from late exposure (Figure 5).

Cruz (2020) described the disappearance of the vent in Gosner Stage 40 as the first external signal of metamorphic change in P. borellii. Moreover, Manzano et al. (2013), for this species, reported the differentiation of ischium/pubis at Gosner Stage 33, cavitation of the acetabulum at Gosner Stage 35, and contact of both pubes at Gosner Stage 41. Concomitantly, the development of the muscles with origin in the ischium and ilium (e.g., the M. iliacus internus, M. tensor fasciae latae, M. iliacus externus) which will insert along the femur occurs at Gosner Stages 36-37 when the iliac shaft grows (Fabrezi et al., 2014). The critical stages in which the abnormal morphologies originated are those in which differentiation of the pelvic girdle takes place (Gosner
Stages 33-35). Skeletons showed asymmetry of pelvic elements, absence of the acetabulum, and deficient elongation of the iliac shaft with the consequence in the incomplete or failure of muscles differentiation. Furthermore, Van Dijk (1959) described spatially (structural) and temporal relationships among limbgirdles tissues, and hypaxial and abdominal muscles, which could be forming the larval vent tube and the adult cloaca. The abnormal morphogenesis of musculoskeletal elements of the pelvic girdle and adjacent tissues (i.e., vent tube) resulting from the endocrine disruption agree with studies that demonstrated an early hormonal sensitivity of limb mesenchyme at limb bud stages (Cai and Brown, 2004) which could be extended to subsequent stages (e.g., when the cartilages of the femur and pelvic girdle are differentiating, and the organization of the thigh musculature begins). 
Methimazole and T4 affected the morphogenesis of the early anlages of pelvic girdles (ischium-pubis and ilium). However, exposure to T4 did not affect chondrogenesis but the shape and growth of the pelvic elements. This fact is consistent with studies that have demonstrated the role of T4 in specific mechanisms regulating cartilage shape and growth (Rose et al., 2015; Rose and Cahill, 2019).

The thyroid hormones are fundamental during anuran metamorphosis. However, tail locomotion (Wassersug, 1975; Handrigan and Wassersug, 2007) and quadruped locomotion (Ročková and Roček, 2005; Manzano et al., 2013; Fabrezi et al., 2014) imply different tissues and developmental processes: tail locomotion disappears and quadruped morphology appears without remodeling. We observed certain parallelism in the response to methimazole and T4 suggesting the occurrence of a temporal and local sensitivity to the $\mathrm{TH}$ in the tissues precursors of limb and girdles during premetamorphic stages (25-35). Furthermore, thyroid gland inhibition by methimazole in Xenopus subtropicalis at larval stages of limb differentiation also prevents the formation of the hypochord, which is part of the urostyle (Senevirathne et al., 2020).

To conclude, we have analyzed endocrine disruption by testing two thyroid active substances (methimazole and T4) during larval development of the frog Pleurodema borellii in mesocosm experiments. We found the concentrations and exposure time affect thyroid gland histomorphology without suppression of glandular activity. The sensitivity of larval stages of premetamorphosis (Gosner Stages 25-36) to disruptors leads to modification of growth and differentiation rates. These changes in developmental rates resemble patterns of larval development of other anuran species. Even when antagonistic disruptors were tested, exposure to a low concentration of methimazole and intermediate concentration of $\mathrm{T} 4$ produced convergent abnormal morphogenesis in pelvic and pectoral girdles, and the sequence of disappearance of the vent tube revealing the role of thyroid axis signals acting appendicular morphogenesis much before metamorphosis.

\section{DATA AVAILABILITY STATEMENT}

The raw data supporting the conclusions of this article will be made available by the authors, without undue reservation.

\section{REFERENCES}

Bancroft, J. D., and Gamble, M. (2002). Theory and Practice of Histological Techniques. Amsterdam: Elsevier Health Sciences.

Buchholz, D. R. (2017). Xenopus metamorphosis as a model to study thyroid hormone receptor function during vertebrate developmental transitions. Mol. Cell. Endocrinol. 459, 64-70. doi: 10.1016/j.mce.2017.03.020

Cai, L., and Brown, D. D. (2004). Expression of type II iodothyronine deiodinase marks the time that a tissue responds to thyroid hormone induced metamorphosis in Xenopus laevis. Dev. Biol. 266, 87-95. doi: 10.1016/j.ydbio. 2003.10.005

Callery, E. M., and Elinson, E. M. (2000). Thyroid hormonedependent metamorphosis in a direct developing frog. Proc. Natl. Acad. Sci. U.S.A. 14, 2615-2620. doi: 10.1073/pnas.05050 1097

\section{ETHICS STATEMENT}

The animal study was reviewed and approved by the Secretaría de Medio Ambiente y Desarrollo Sustentable, Gobierno de la Provincia de Salta, Argentina, and adhered to the legal requirements of Argentine laws (File number 227216600/064/2016).

\section{AUTHOR CONTRIBUTIONS}

MF contributed to the conception, design, performed the experiments and morphological records, and wrote the first draft of the manuscript. JC was responsible for histology and statistics and wrote sections of the manuscript. MF and JC contributed to manuscript revision, read, and approved the submitted version. Both authors contributed to the article and approved the submitted version.

\section{FUNDING}

MF and JC were funded by the Consejo Nacional de Investigaciones Científicas y Técnicas (CONICET). This study was supported by the Agencia Nacional de Promoción Científica y Tecnológica (PICT 2018-1383) to MF. The funders had no role in the design of the study and collection, analysis, and interpretation of data and in writing the manuscript.

\section{ACKNOWLEDGMENTS}

MF was grateful to Veronica Laura Lozano for some helpful suggestions for experimental mesocosm designs some years ago. The permissions to collect and maintain the animals in the laboratory were obtained from the Secretaría de Medio Ambiente y Desarrollo Sustentable, Gobierno de la Provincia de Salta, Argentina, and adhered to the legal requirements of Argentine laws (File number 227-216600/064/2016). Pleurodema borellii is a frog commonly available with category of least concerned and stable populations for IUCN.

Choi, J., Ishizuya-Oka, A., and Buchholz, D. R. (2017). Growth, development, and intestinal remodeling occurs in the absence of thyroid hormone receptor $\alpha$ in tadpoles of Xenopus tropicalis. Endocrinology 158, 1623-1633. doi: 10.1210/en. 2016- 1955

Cruz, J. C. (2020). Histo-morphology of the thyroid gland during the larval development of Pleurodema borellii (Anura, Leptodactylidae). Acta Zool. 1-9. doi: 10.1111/azo.12354

Cruz, J. C., and Fabrezi, M. (2019). Histology and microscopic anatomy of the thyroid gland during the larval development of Pseudis platensis (Anura, Hylidae). J. Morphol. 281, 122-134. doi: 10.1002/jmor.21085

de Sá, R. O., Grant, T., Camargo, A., Heyer, W. R., Ponssa, M. L., and Stanley, E. (2014). Systematics of the neotropical genus Leptodactylus Fitzinger, 1826 (Anura: Leptodactylidae): phylogeny, the relevance of non-molecular evidence, and species accounts. S. Am. J. Herpetol. 9, S1-S128. doi: 10.2994/SAJHD-1300022.1 
Degitz, S. J., Holcombe, W. G., Flynn, K. M., Kosian, P. A., Korte, J. J., and Tietge, J. E. (2005). Progress towards development of an amphibian-based thyroid screening assay using Xenopus laevis. Organismal and thyroidal responses to the model compounds 6-propylthiouracil, methimazole, and thyroxine. Toxicol. Sci. 87, 353-364. doi: 10.1093/toxsci/kfi246

Emerson, S. B. (1988). The giant tadpole of Pseudis paradoxa. Biol. J. Linn. Soc. 34, 93-104. doi: 0.1111/j.1095-8312.1988.tb01951.x

Etkin, W. (1936). The phenomena of anuran metamorphosis. III. The development of the thyroid gland. J. Morphol. 59, 69-89. doi: 0.1111/j.1095-8312.1988. tb01951.x

Fabrezi, M. (2011). Heterochrony in growth and development in anurans from the Chaco of South America. Evol. Biol. 38, 390-411. doi: 10.1007/s11692-0119128-5

Fabrezi, M., and Cruz, J. C. (2014). Ontogeny of the thyroid glands during larval development of South American horned frogs (Anura, Ceratophryidae). Evol. Biol. 41, 606-618. doi: 10.1007/s11692-014-9292-5

Fabrezi, M., Lozano, V. L., and Cruz, J. C. (2019). Differences in responsiveness and sensitivity to exogenous disruptors of the thyroid gland in three anuran species. J. Exp. Zool. B Mol. Dev. Evol. 332, 279-293. doi: 10.1002/jez.b.22908

Fabrezi, M., Manzano, A. S., Abdala, V., and Lobo, F. (2014). Anuran locomotion: ontogeny and morphological variation of a distinctive set of muscles. Evol. Biol. 41, 308-326. doi: 10.1007/s11692-014-9270-y

Fabrezi, M., Quinzio, S. I., and Goldberg, J. (2009). The giant tadpole and delayed metamorphosis of Pseudis platensis Gallardo, 1961 (Anura. Hylidae). J. Herpetol. 43, 228-243. doi: 10.1007/s11692-014-9292-5

Gosner, K. (1960). A simplified table for staging anurans embryos and larvae, with notes on identification. Herpetologica 16, 183-190.

Grim, K. C., Wolfe, M., Braunbeck, T., Iguchi, T., Ohta, Y., Ttooi, Y., et al. (2009). Thyroid histopathology assessments for the amphibian metamorphosis assay to detect thyroid-active substances. Toxicol. Pathol. 37, 415-424. doi: 10.1177/ 0192623309335063

Handrigan, G. R., and Wassersug, R. J. (2007). The anuran Bauplan: a review of the adaptive, developmental, and genetic underpinnings of frog and tadpole morphology. Biol. Rev. 82, 1-25. doi: 10.1111/j.1469-185X.2006.00001.x

Hanken, J., and Summers, C. H. (1988). Skull development during anuran metamorphosis: III. Role of thyroid hormone in chondrogenesis. J. Exp. Zool. 246, 156-170. doi: 10.1002/jez.1402460208

Jennings, D. H., and Hanken, J. (1998). Mechanistic basis of life history evolution in anuran amphibians: thyroid gland development in the direct-developing frog, Eleutherodactylus coqui. Gen. Comp. Endocr. 111, 225-232. doi: 10.1006/gcen. 1998.7111

Kupferberg, S. J. (1997). The role of larval diet in anuran metamorphosis. Am. Zool. 37, 146-159. doi: 10.1093/icb/37.2.146

Laslo, M., Denver, R. J., and Hanken, J. (2019). Evolutionary conservation of thyroid hormone receptor and deiodinase expression dynamics in ovo in a direct-developing frog, Eleutherodactylus coqui. Front. Endocrinol. 10:307. doi: 10.3389/fendo.2019.00307

Manzano, A., Abdala, V., Ponssa, M. L., and Soliz, M. (2013). Ontogeny and tissue differentiation of the pelvic girdle and hind limbs of anurans. Acta Zool. 94, 420-436. doi: 10.1111/j.1463-6395.2012.00571.x

Martoja, R., and Martoja-Pierson, M. (1970). Técnicas de Histología Animal. Barcelona: Toray-Masson.

Naumann, B., Schweiger, S., Hammel, J. U., and Müller, H. (2020). Parallel evolution of direct development in frogs - skin and thyroid gland development in African squeaker frogs (Anura: Arthroleptidae: Arthroleptis). Dev. Dyn. 250, 584-600. doi: 10.1101/2020.09.07.286476

Opitz, R., Hartmann, S., Blank, T., Braunbeck, T., Lutz, I., and Kloas, W. (2006). Evaluation of histological and molecular endpoints for enhanced detection of thyroid system disruption in Xenopus laevis tadpoles. Toxicol. Sci. 90, 337-348. doi: 10.1093/toxsci/kfj083

Phuge, S., Sequeira, A., and Pandit, R. (2021). Effect of ethylenethiourea on metamorphosis and ovary development: a comparative study of three larval frogs. J. Exp. Zool. A Ecol. Integr. Physiol. 335, 469-476. doi: 10.1002/jez.2464

Roček, Z., Böttcher, R., and Wassersug, R. J. (2006). Gigantism in the tadpoles of the Neogene frog Paleobatrachus. Paleobiology 32, 666-675. doi: 10.1666/05073.1

Ročková, H., and Roček, Z. (2005). Development of the pelvis and posterior part of the vertebral column in the Anura. J. Anat. 206, 17-35. doi: 10.1111/j.00218782.2005.00366.x
Roelants, K., Haas, A., and Bossuyt, F. (2011). Anuran radiations and the evolution of tadpole morphospace. Proc. Natl. Acad. Sci. U.S.A. 108, 8731-8736. doi: $10.1073 /$ pnas. 1100633108

Rose, C. S. (2021). Amphibian hormones, calcium, physiology, bone weight, and lung use call for inclusive approach to understanding ossification sequence evolution. Front. Ecol. Evol. 9:620971. doi: 10.3389/fevo.2021.620971

Rose, C. S., and Cahill, J. W. (2019). How thyroid hormones and their inhibitors affect cartilage growth and shape in the frog Xenopus laevis. J. Anat. 234, 89-105. doi: $10.1111 /$ joa.12897

Rose, C. S., Murawinski, D., and Horne, V. (2015). Deconstructing cartilage shape and size into contributions from embryogenesis, metamorphosis, and tadpole and frog growth. J. Anat. 226, 575-595. doi: 10.1111/joa.12303

Rot-Nikcevic, I., and Wassersug, R. J. (2004). Arrested development in Xenopus laevis tadpoles: how size constrains metamorphosis. J. Exp. Biol. 207, 21332145. doi: 10.1242/jeb.01002

Rot-Nikcevic, I., and Wassersug, R. J. (2003). Tissue sensitivity to thyroid hormone in athyroid Xenopus laevis larvae. Dev. Growth Differ. 45, 321-325. doi: 10.1046/ j.1440-169x.2003.00700.x

Schreiber, A. M., Liquan, C., and Brown, D. D. (2005). Remodeling of the intestine during metamorphosis of Xenopus laevis. Proc. Natl. Acad. Sci. U.S.A. 102, 3720-3725. doi: 10.1073/pnas.0409868102

Senevirathne, G., Baumgart, S., Shubin, N., Hanken, J., and Shubin, N. H. (2020). Ontogeny of the anuran urostyle and the developmental context of evolutionary novelty. Proc. Natl. Acad. Sci. U.S.A. 117, 3034-3044. doi: 10.1073/pnas. 1917506117

Shi, Y.-B. (2000). Amphibian Metamorphosis: From Morphology to Molecular Biology, 1st Edn. New York, NY: Wiley-Liss, 288.

Skelly, D. K., and Kiesecker, J. M. (2001). Venue and outcome in ecological experiments: manipulations of larval anurans. Oikos 94, 198-208. doi: 10.1034/ j.1600-0706.2001.t01-1-11105.x

Smirnov, S. V., and Vassilieva, A. B. (2014). Thyroid hormones in the skeletogenesis and accessory sources of endogenous hormones in Xenopus laevis (Amphibia; Anura) ontogeny: experimental evidence. Dokl. Biol. Sci. 455, 136-138. doi: 10.1134/S0012496614020185

Smirnov, S. V., and Vassilieva, A. B. (2009). Number of ossification centers in the anuran cranial bones depends upon the rate of development: experimental evidence. Russ. J. Herpetol. 16, 167-176.

Trueb, L. (1993). "Patterns of diversity in the Lissamphibian skull," in The Vertebrate Skull: Patterns of Structural and Systematic Diversity, Vol. 2, eds J. Hanken, and B. K. Hall (Chicago, IL: University of Chicago Press), 255-343.

Van Dijk, D. E. (1959). On the cloacal region of Anura in particular of larval Ascaphus. Ann. Univ. Stell. 35A, 169-249.

Wassersug, R. J. (1975). The adaptive significance of the tadpole stage with comments on the maintenance of complex life cycles in anurans. Am. Zool. 15, 405-417. doi: 10.1093/icb/15.2.405

Wassersug, R. J. (1976). A procedure for differential staining of cartilage and bone in whole formalin fixed vertebrates. Stain Technol. 51, 131-134. doi: 10.3109/ 10520297609116684

Yaoita, Y. (2019). Tail resorption during metamorphosis in Xenopus tadpoles. Front. Endocrinol. 10:143. doi: 10.3389/fendo.2019.00143

Conflict of Interest: The authors declare that the research was conducted in the absence of any commercial or financial relationships that could be construed as a potential conflict of interest.

Publisher's Note: All claims expressed in this article are solely those of the authors and do not necessarily represent those of their affiliated organizations, or those of the publisher, the editors and the reviewers. Any product that may be evaluated in this article, or claim that may be made by its manufacturer, is not guaranteed or endorsed by the publisher.

Copyright (c) 2021 Fabrezi and Cruz. This is an open-access article distributed under the terms of the Creative Commons Attribution License (CC BY). The use, distribution or reproduction in other forums is permitted, provided the original author(s) and the copyright owner(s) are credited and that the original publication in this journal is cited, in accordance with accepted academic practice. No use, distribution or reproduction is permitted which does not comply with these terms. 